\title{
Evidence-based Education: Why it is a Problematic Platform for Educational Research to Participate in Education Policymaking
}

\author{
Yunfei Ma
}

\author{
University of Durham \\ yunfei.ma@durham.ac.uk
}

\begin{abstract}
This paper argues that the current evidence-based movement in education should move towards a knowledge-based direction. The discussions cover why the existing movement has privileged educational research that adopts experimental designs, how research participates in education policymaking and what problems it raises. Experimental evidence on educational programs and interventions is not a panacea, nor does it offer a cookbook that policymakers can uncritically follow. Diversity in educational research is necessary for educational research to inform and improve school policies in a healthy manner.
\end{abstract}

Keywords: evidence-based education, professional judgement, education policymaking, experimental designs

\section{INTRODUCTION}

Wiseman observed in 2010 that in several countries, there has been a popular idea that practitioners within the education sphere should consult research evidence to improve their work[20] Although, as Davies argued in 1999(a), there are multiple approaches to understanding "evidence-based education"[6], it is nowadays generally believed that the concept refers to the development of school policies and the teaching practice based upon evidence from experimental research on the effectiveness of educational programs[16](Slavin, 2002a). As a result of this evidence-based movement in education, educational research that adopts experimental designs appears to have acquired a privileged position. This article draws on Paul Trowler's engineering model and previous critiques of experimental educational research to analyse the research-policy relationship. Though, according to Slavin's statement above, there is an agreement on what evidence-based education implies in general, the relationship between educational research and education polices under the framework is hardly explored. By demonstrating how evidence-based education in practice deviated from its original intention and what problems followed, the study expects to enlarge the academic knowledge base. Moreover, the article is also socially significant as it sheds light on the danger caused by education policymakers' narrowly utilitarian attitude towards educational research.

\section{UNEARTHING THE PRIVILEGED POSITION OF EDUCATIONAL RESEARCH THAT ADOPTS EXPERIMENTAL DESIGNS}

Inspired and encouraged by the significant progress in medicine after it became evidence-based, scholars introduced the movement into education in expectation of a similar outcome[16] (Slavin, 2002b, p.16). According to Parsons and Burkey (2011), the UK achieved significant progress in curriculum designs and pedagogy thanks to the Teaching and Learning Research Program, which is managed by the Economic and Social Research Council and chiefly intended for applying findings from educational research (mainly experimental) to education policymaking[14]. More recently, there has been an Education Endowment Foundation in the UK, comprised of several government-funded research centres that primarily focus on applying evidence from experimental studies to public services, education included[5] (Cowen, 2019a, p.82).

However, although previous literature reported that the collaboration between experimental studies and education policymaking yielded positive outcomes, there 
is danger beneath the promising veneer: educational research risks being subject to education policies as long as policymakers decide what research evidence shall be acknowledged and dismissed. Paul Trowler proposed an engineering model in 2003, arguing that research should chiefly aim at proposing solutions to policy-related issues[17]. In terms of education, there has been "a revolution in the relations between government and the research community to support the government's modernising agenda, which was coupled with an emphasis on research that demonstrates what types of policy initiatives are likely to be most effective"[3] (Blunkett, 2000, p.21). In other words, education policymakers want research to offer evidence on what policies work well and what programs produced promising outcomes. As Orland neatly put it in 2009 (p.118), "educational research is much more likely to be paid attention to by educational policy leaders when it buttresses arguments about particular policy directions or prescriptions already being advocated, thus furthering a particular political/policy position. It is research as ammunition not as knowledge discovery."[13] As a result, whether education policymakers recognise it or not, they promoted a worrisome "standardisation of research purposes, procedures, reporting and dissemination"[1] because research generating findings that are in line with political agendas has a disproportionally higher possibility of being deemed as being informative (Ball, 2001, p.266-267). Although the critics may fail to recognise that the engineering model is not the only way research and policies work together, which will be discussed later, their thoughts cannot be dismissed as fallacies. It is, therefore, safe to conclude that under the evidence-based framework, experimental research has received excessive attention from education policymakers. Cowen wrote (2019b) that compared with non-experimental studies, the experimental one is usually more understandable even without domain-specific knowledge as it isolates multiple variables, pins down and reports their effects respectively[5]. Provided that education policymakers are mostly concerned with finding out from available evidence what can be done[10], it is likely that they would prioritise educational studies that do not require much specialised expertise to comprehend over those that may.

\section{GROUNDS BASED UPON WHICH THE EVIDENCE-BASED MOVEMENT COULD BE CHALLENGED}

The fact that evidence-based education produced positive outcomes in the UK, as argued above, does not exempt it from being examined critically. In fact, two issues overshadow its seemingly promising prospect, one on the research side and the other on the policymaking side. On the one hand, while education policymakers can be selective about their use of evidence, researchers conducting experimental studies can be selective as well, albeit about the production of evidence. For instance, Every-Palmer and Howick (2014) stated that researchers occasionally use preferential controls to enhance the influences of certain variables, hoping that the results would appear more straightforward and often, more persuasive[8]. Murnane and Willett once expressed a similar opinion in 2011 that findings from experimental research could be misguiding because whether an educational program or intervention is found to be "effective" greatly depends on discretional factors[12]. In other words, there is a great possibility that evidence from experimental research is seemingly attractive but essentially misleading.

The issue on the research side is complicated if the complexity of school and classroom environment is considered. In a controlled and laboratory-like setting, experimental researchers could establish a relatively secure relationship between a particular intervention or variable and its impact on the research outcome by ruling out external interferences. However, the uniqueness of each teaching situation, including the variances in students' learning abilities and the teaching contents, suggests that the laboratory settings have a rather limited chance of being replicated in schools and classrooms. Cartwright claims (2013) that few researchers are confident that the causal effects they discovered are immune to changes in environments[4]. This problem further calls the privileged position of experimental studies into question: when an education policy turns out to be unsatisfactory, the policymakers would find it exceedingly difficult to know whether the experimental evidence they refer to is flawed or the educational program's ability to work is undermined in a new context.

On the other hand, in addition to the problems with experimental research, the issue with education policymakers merits special notes as well. Analysis above based on the engineering model points out the research-policy relationship under the evidence-based education framework: educational research participates in producing new education policies and amending current ones by providing policymakers with evidence on what educational programs or interventions worked well. However, Gorard commented in 2005 that education policymakers had demonstrated a worrying tendency to rely on experimental evidence heavily and even 
unquestioningly[9]. While experimental evidence can indeed serve as a consultant on political decision-making, it may weaken education policymakers' critical thinking ability if not used properly. As John Dewey (1922) famously put it in Human Nature and Conduct, thinking is the "dramatic rehearsal of various competing possible lines of action"[7] (p.132). In terms of education policymakers, they need to consider all possible solutions to the same issue and decide on the most appropriate one. What experimental educational research does is making "the process of choosing more intelligent than it would have been in the case of blind trial and errors" [2] (Biesta, 2007, p.15). In other words, experimental evidence should help education policymakers to come up with a better solution instead of becoming the solution itself. With the previously mentioned arguments being considered, it appears that the limited capacity of experimental research and education policymakers' unrealistic expectation of experimental evidence collectively render the evidence-based education exceptionable.

\section{TOWARDS DIVERSITIES OF EDUCATIONAL RESEARCH}

The fundamental problem with evidence-based education lies not in the limitations of experimental studies or in how policymakers deal with experimental evidence. Instead, it is the instrumental and narrowly utilitarian perspective on educational research that is the most concerning. Lingard (2013) states that while some educational research "takes policy problems as given", there is also research that "sees the deconstruction of the problem-construction work of policy as a necessary step in policy analysis"[11] (p.120). That is to say, educational research not only contributes to education policies under the engineering framework as a significant source of solutions, but it also alters policymakers' perceptions of certain issues and how they approach them. The second process could take time for its influence to manifest itself, and the majority of education policymakers may not even recognise that their political dispositions have gone through a fundamental change. For instance, for most education policymakers in the UK, gender equality among students is an issue too significant to dismiss. According to Riddell and Salisbury (2003), such a transformation in the political environment would not be possible without the accumulation of various types of educational research, including case studies on students' painful experiences of being sexually disadvantaged and of being treated unfairly due to their gender choices[15]. The example implicitly implies that compared with educational research that offers experimental evidence, other types of research have a less direct but no less important way of contributing to education policies: they lead to the re-conceptualisation of policy-related issues by gradually encouraging education policymakers to cast off outdated and often improper assumptions. In the last century, Weiss (1979) made a prophecy-like argument that research could enlighten policymakers by shaping the conventions they conform to, and enlightenment in this sense is usually not perceivable until it is embodied by a big idea, such as the gender equality concept mentioned above[18].

More importantly, there can be little certainty about what type of educational research will finally facilitate policymaking or transform the political environment at large. Thus, respecting and promoting the diversity of education research, especially of research purposes and designs, are of paramount importance. As for education policymakers, it is crucial that they realise although some educational studies are closely linked to their practice because of the straightforward, experimental evidence they provide, other research is offering assistance as well, albeit indirectly and incrementally. It is worth pointing out that educational research also enlightens policymakers in the form of criticism. For instance, educational research revealing shortcomings of existing policies could strengthen "the public mind on education to increase 'resistance' to superficial but seemingly attractive policies"[19] in the future (Whitty, 2006, p.170). Unfortunately, the role of educational research as social criticism is a complicated matter that involves various stakeholders, which can only be briefly touched on here.

The initial intention of evidence-based education, as Davies put it (1999b), is to give education policymakers a solid "basis upon which they make professional judgements and deploy their expertise"[6] (p.118). Both the research-as-ammunition and research-as-solutions are deviations from the very starting point as they marginalise educational research whose findings are not in accordance with political agendas. Recognising the value of different types of research and appreciating the usefulness of all relevant educational studies are what an evidence-based educational practice should look like. It seems that a knowledge-based education better summarises what an "evidence-based education" wishes to achieve initially. After all, it is educational research as knowledge advancement not as buttresses for particular policy positions that drove and will continue to drive development in school policies. 


\section{CONCLUSION}

In conclusion, the evidence-based movement privileges experimental educational research mainly because of its policy-friendliness. However, the restrictions of the research itself, along with policymakers' excessive expectation of and narrowly utilitarian view on experimental evidence suggest that the evidence-based education is flawed in practice. More importantly, education policymakers tend to dismiss educational research that does not directly support their political positions. The consequence of such practices is particularly harmful to the diversity of the research community. Maybe it is time to displace evidence-based education with a knowledge-based one, where educational research and education polices flourish together in a mutually respectful manner.

\section{ACKNOWLEDGMENTS}

The author wishes to thank Professor Liam Gearon at the University of Oxford and Doctor Chenkai Chi at the University of Windsor for their excellent lectures and tutorials. Professor Gearon provided outstanding guidance on the relationships between education and other relevant areas, including politics and religion, and how these relationships have developed historically. Doctor Chi offered detailed and useful tutorials on the gender equality issue and other education-related topics. Their expertise and dedication to education contributed tremendously to this article.

\section{REFERENCES}

[1] Ball, S.J. (2001). 'You've been NERFed!' Dumbing down the academy: National Educational Research Forum: 'a national strategy? consultation paper': a brief and bilious response. Journal of education policy. Vol.16(3), 265-268. DOI: 10.1080/02680930110041393.

[2]Biesta, G. (2007). Why "what works" won't work: Evidence-based practice and the democratic deficit in educational research. Educational Theory, Vol.57(1), 1-23. DOI: $10.1111 / \mathrm{j} .1741-$ 5446.2006 .00241

[3]Blunkett, D. (2000). Influence or irrelevance: can social science improve government? London: Department for Education and Employment.

[4]Cartwright, N. (2013). Knowing What We Are Talking About: Why Evidence Doesn't Always
Travel. Evidence \& policy, Vol.9(1), 97-112. DOI: 10.1332/174426413X662581.

[5]Cowen, N. (2019). For whom does "what works" work? The political economy of evidence-based education. Educational research and evaluation, Vol.25(1-2), 81-98. DOI: 10.1080/13803611.2019.1617991.

[6]Davies, P. (1999). What is Evidence-based Education?. British journal of educational studies, Vol.47(2), 108-121. DOI: 10.1111/14678527.00106.

[7]Dewey, J. (1922). Human nature and conduct. London: George Allen \& Unwin.

[8]Every-Palmer, S. and Howick, J. (2014). How evidence-based medicine is failing due to biased trials and selective publication. Journal of Evaluation in Clinical Practice, Vol.20(6), 908-916. DOI: $10.1111 /$ jep.12147.

[9]Gorard, S. (2005). Academies as the 'future of schooling': is this an evidence-based policy? Journal of education policy. Vol.20(3), 369-377. DOI: 10.1080/02680930500117321.

[10]Levin, B. (2005). Reforming education: from origin to outcomes. London: Routledge.

[11]Lingard, B. (2013). The impact of research on education policy in an era of evidence-based policy. Critical studies in education. Vol.54(2), 113-131. DOI: $10.1080 / 17508487.2013 .781515$.

[12]Murnane, R.J. and Willett, J.B. (2011). Methods matter: improving causal inference in educational and social science research. Oxford, England: Oxford University Press.

[13]Orland, M. (2009). Separate orbits: The distinctive worlds of educational research and policymaking. In G. Skyes, B. Schneider, D. Plank and T. Ford (Eds.), Handbook of education policy research (pp.113128). New York: Routledge.

[14]Parsons, D.J. and Burkey, S. (2011). Evaluation of the Teaching and Learning Research Programme (Second Phase). Retrieved from https://esrc.ukri.org/files/research/research-andimpact-evaluation/teaching-and-learning-researchprogramme/.

[15]Riddell, S. and Salisbur, J. (2003). Gender, Policy and Educational Change: Shifting Agendas in the $U K$ and Europe. London: Routledge. 
[16]Slavin, R.E. (2002). Evidence-based education policies: Transforming educational practice and research. Educational Researcher, Vol. 31(7), 15-21. Retrieved from https://journals.sagepub.com/doi/pdf/10.3102/0013 189X031007015?casa_token=t_eiQUCV6M0AAA AA:1BtdzDlKDgJ1TggUtoxG5BldAQJ1XYH4Zov RxYmVtcCNrumKU7MflEORl-XNaG9W22q5qu6_NI.

[17]Trowler, P. (2003). 2nd education policy. London: Routledge.

[18]Weiss, C.H. (1979). The Many Meanings of Research Utilization. Public Administration Review. Vol.39(5), 426-431. DOI: 10.2307/3109916.

[19]Whitty, G. (2006). Education(al) research and education policy making: is conflict inevitable?. British Educational Research Journal. Vol.32(2), 159-176. DOI: 10.1080/01411920600568919.

[20]Wiseman, A. W. (2010). The Uses of Evidence for Educational Policymaking: Global Contexts and International Trends. Review of research in education, Vol.34(1), 1-24. DOI: 10.3102/0091732X09350472. 